\title{
Trends in HIV incidence in homosexual men in developed countries
}

\author{
Andrew E. Grulich ${ }^{\mathrm{A}, \mathrm{B}}$ and John M. Kaldor ${ }^{\mathrm{A}}$

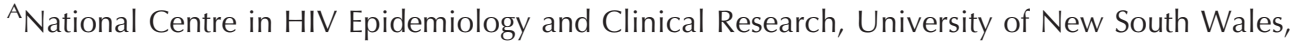 \\ Sydney, NSW 2010, Australia. \\ ${ }^{B}$ Corresponding author. Email: agrulich@nchecr.unsw.edu.au
}

\begin{abstract}
Objectives: To describe trends in HIV notifications and in other measures of HIV incidence in homosexual men in developed countries. Methods: A literature search was conducted using PubMed. In addition to the peer-reviewed literature, data on HIV surveillance trends were sought by searching websites of surveillance authorities in developed countries. Results: The availability of long-term HIV surveillance data varied considerably. However, in almost all jurisdictions in which such data were available, notifications of new HIV diagnoses among homosexual men have increased, mostly since the late 1990s. The magnitude of this increase varied, but was more than 50\% in many countries. There were much fewer data available on trends in direct measures of HIV incidence in homosexual men, and increases in HIV testing rates may have contributed to the increases in HIV diagnoses in many countries. However, since the late 1990s, several clinic- and community-based cohort studies in Europe and North America reported increasing incidence. Conclusion: There were increases in HIV notifications in homosexual men in almost all developed countries, starting in the late 1990s and continuing to 2006. Although increases in HIV testing probably contributed to the increases in some settings, limited cohort data do support the existence of a true increase in HIV incidence in European and North American countries. Improved monitoring of HIV incidence in homosexual men at the population level is required to allow more timely assessment of the drivers underlying such trends.
\end{abstract}

Additional keywords: cohort studies, HIV surveillance, HIV testing.

\section{Introduction}

In Australia, HIV continues to be an infection that disproportionately affects homosexual men. In $2005,76 \%$ of new HIV diagnoses and $88 \%$ of newly acquired HIV infections were in homosexual men. ${ }^{1}$ Australia is credited with having an excellent public health response to HIV infection, and rates of notification of HIV diagnoses in homosexual men declined consistently between the mid 1980s and 1998. ${ }^{1}$ However, recently this success has been challenged. Between 2000 and 2006 , the number of HIV diagnoses in homosexual men increased by $31 \%$. In addition, there has been a marked divergence in trends between the three largest jurisdictions in Australia. In New South Wales, diagnosis rates among homosexual men have stabilised since 1999, whereas in Victoria, rates have doubled. In Queensland, an intermediate pattern has been shown. In 2006, the per capita rate of HIV diagnosis in homosexual men was higher in Victoria than in New South Wales for the first time since the beginning of the epidemic. ${ }^{2}$

In the light of the increasing diagnosis of HIV in homosexual men in Australia, and to inform the public health response to this increase, we performed a review of trends in HIV diagnoses and markers of HIV incidence in homosexual men in other developed country settings.

\section{Methods}

A search was performed, in July 2007, in PubMed, with combinations of the search terms 'HIV', 'AIDS', 'homosexual men', 'men who have sex with men', 'gay men', 'incidence', 'prevalence' and a search of reference lists of relevant papers. In addition, as much HIV surveillance data are not published in the peer-reviewed literature, websites of HIV surveillance authorities in the USA, Canada, the UK, and continental Europe were searched for non-peer-reviewed publications of surveillance data.

In different countries, different terms were used to define for surveillance and research purposes men who reported the sexual risk behaviour of interest. These terms included 'homosexual men', 'homosexual and bisexual men', 'gay men' and 'men who have sex with men'. In the present paper, for simplicity we have used the term 'homosexual men' but it is important to note that surveillance data generally report information about behaviour and not identity. In contrast, most community-based cohort studies have been of homosexually-identified men.

For the purposes of presentation, data were grouped as being based on routine surveillance, or being derived from measures of HIV incidence in epidemiological studies. We have reported data from epidemiological studies separately if they were:

(a) longitudinal measures of incidence from clinic or community-based studies, or

(b) measures of incidence calculated by using the serologic testing algorithm for recent HIV-1 seroconversion (STARHS) on a blood specimen collected at a single point of time. ${ }^{3}$ 
Two less direct measures were also included. First, as rates of testing for HIV may influence rates of diagnosis of HIV, we included studies which reported testing rates for HIV. Second, as data on trends in HIV prevalence in homosexual men may reflect changes in incidence, particularly in the young, we also included these studies.

The focus of this article is on trends since the late 1990s. Data were considered for inclusion if they contained data relevant to the period after 1996, when highly active anti-retroviral therapy first became widely available. Data from the last complete year were included, and this varied substantially between countries.

\section{Results}

Europe

\section{Surveillance data}

In $2005,35 \%$ of new HIV diagnoses in Western Europe, and $\sim 10 \%$ of those in central Europe, were in men who have sex with men. ${ }^{4}$ In contrast, less than $1 \%$ of cases in Eastern Europe were in men who have sex with men. Among countries with data on risk behaviour available between 1998 and 2005, the number of HIV diagnoses among men who have sex with men increased by $55 \%$ in Western Europe and $133 \%$ in central Europe. ${ }^{4}$ The increases in diagnoses in HIV in men who have sex with men in Western Europe have occurred in most individual countries with available data including Denmark, Finland, Germany, Switzerland, the UK and Belgium. No increase was observed in two small jurisdictions, Ireland and Greece. ${ }^{5,6}$ No data on HIV notification trends were available for Spain, Italy or France.

\section{Data from epidemiological studies}

A significant increase in HIV incidence has been reported among homosexual men who were repeat sexually transmitted disease (STD) clinic attenders at several European sites. The increase was from 1.1 to 2.2 per 100 person years (PY) between 1996 and 2000 in Madrid. ${ }^{7,8}$ More recent increases have been described in Rome (2.8 to 5.0 per 100 PY between 1996-1999 and 2000-2003) and Valencia (1.9 to 3.3 per 100 PY between 2002 and 2003). ${ }^{9,10}$ In two community-based cohort studies in the Netherlands, incidence was between 1.2 and 1.5 per $100 \mathrm{PY}$, and was stable to 2005 . $^{11}$

There have been a few studies in Europe which have estimated HIV incidence using the STARHS assay. In Amsterdam, based on samples collected during an annual unlinked anonymous HIV prevalence survey among STD clinic attenders, the incidence between 1991 and 1998 was $1.8 \%$ per year. In the period 1999-2005, the estimated incidence was $3.8 \%$ per year, and the increase was significant overall, and in those aged 34 years and older. ${ }^{1,12} \mathrm{~A}$ study based on samples collected as part of an unlinked anonymous HIV prevalence survey of homosexual men attending UK genito-urinary medicine (GUM) clinics during 1996-2001 estimated an incidence of HIV of between $1.5 \%$ and $3.3 \%$ per year. ${ }^{13,14}$ There was a non-significant increase from a nadir of $1.5 \%$ in 1999 to $3.0 \%$ in $2004 .^{15}$

Cross-sectional studies of homosexual men in large cities in Western Europe have reported HIV seroprevalence rates of 10 to $15 \%$ in the UK, France, Denmark, Germany and
Switzerland, and somewhat more than this in Spain. ${ }^{16}$ In the $\mathrm{UK}$, there was a marked recent increase in CD4 positive lymphocyte count at HIV diagnosis, with the proportion presenting with a CD4 count of more than 700 increasing from $12 \%$ in 1997 to $26 \%$ in 2004. In addition, the proportion of homosexual men attending GUM clinics who received voluntary HIV testing increased from 46\% in 1997 to $80 \%$ in 2004 . These data suggest that the increases in HIV diagnoses in the UK may be due, at least in part, to earlier testing for HIV. ${ }^{15}$ The proportion of homosexual men who have never been HIV tested remains relatively high in some European countries including Germany $(30 \%$ of those recruited in $2006)^{17}$ and the Netherlands (46\% of those recruited in 2002). ${ }^{18}$

\section{Canada}

\section{Surveillance data}

In Canada, new diagnoses of HIV increased by $20 \%$ between 2001 and 2004, and the proportion of HIV diagnoses that occurred in homosexual men increased to $45 \%$ in $2004 .{ }^{19}$ In British Columbia, reliable data on HIV diagnoses are available since the mid 1990s. In that province, the total number of people diagnosed with HIV remained roughly stable between 1998 and 2004, but the number of HIV diagnoses in homosexual men increased by $46 \%{ }^{20}$ Over the same period the annual number of HIV diagnoses in homosexual men in Ontario increased by $28 \%{ }^{21}$

\section{Data from epidemiological studies}

The incidence of HIV in community-based studies of gay men was estimated to be 0.56 per 100 PY during 1996-2001 in Montreal, $^{22}$ and 1.4 per $100 \mathrm{PY}$ in Vancouver during $1995-2000 .^{23}$ A linkage study of men undergoing voluntary diagnostic HIV testing in Ontario reported annual incidence rates of 0.79 to 1.4 per $100 \mathrm{PY}$ among homosexual men during 1992-2000. ${ }^{24}$ The Vancouver and Ontario studies, but not the Montreal study, reported significant increases in HIV incidence rates over time.

In venue-based samples of gay men across Canada in 2002, the self-reported HIV prevalence was approximately $13 \%$ in Toronto and Montreal and in British Columbia. ${ }^{25}$ There are few data on HIV testing in Canada. However, an Ontario-based community survey reported that rates of HIV testing have increased. In 1990, 65\% of men reported being tested for HIV previously, and this increased to $80 \%$ in a 2002 study. $^{26}$

\section{USA}

\section{Surveillance data}

Long-term trends in HIV surveillance are not available in most of the USA, but HIV surveillance data are available for 29 states from $1999^{27}$ and 33 states since $2001 .^{28}$ In homosexual men, HIV diagnoses increased $17 \%$ between 1999 and 2002, and between 2001 and 2005 they increased a further $15 \%$. During this period, HIV diagnoses in people reporting other risk behaviours declined. By 2001-2005, 48\% of all HIV diagnoses were in homosexual men. ${ }^{28-30}$ 


\section{Data from epidemiological studies}

There have been many community-based cohort studies of HIV incidence based on repeat testing among homosexual men in the USA. A review of HIV incidence in 20 such studies conducted between 1978 and 1999 concluded that HIV incidence peaked in the early to mid 1980s (rates of 5-20 per $100 \mathrm{PY}$ ) and declined but remained high, between 2 and 4 per $100 \mathrm{PY}$, in the $1990 \mathrm{~s} .{ }^{31}$ Only one community-based cohort study conducted in the 21 st century has been reported, and that found a similar incidence, of 2.1 per $100 \mathrm{PY}^{32}$

Generally higher HIV incidences, mostly between 3 and $10 \%$ per year, have been described in several studies which used the STARHS algorithm to estimate HIV incidence from blood samples collected by US STD clinics. ${ }^{31}$ A San Franciscobased study reported constant HIV incidence, at approximately $4 \%$ per year, at its major public STD clinic, but no HIV surveillance data were available to confirm this trend. ${ }^{33}$

A venue-based cross-sectional study of young men who have sex with men (MSM) conducted in major American cities in 1994-1998 found a high prevalence of HIV in young gay men, of $8.6 \%$ in those aged $20-22$ and $5.6 \%$ in those aged $15-19$. Prevalence was higher in blacks. ${ }^{34} \mathrm{~A}$ community-based survey of HIV prevalence of homosexual men in five major cities in the USA in 2004-2005 reported HIV prevalence based on rapid testing of blood specimens of $25 \%$, and this ranged from $18 \%$ in Miami and New York City to $40 \%$ in Baltimore. ${ }^{35}$ In San Francisco, a telephone survey in 2002 found that selfreported HIV prevalence in homosexual men was $27 \% .{ }^{36}$ It was $19 \%$ in a Californian state-wide telephone survey in the same year. ${ }^{37}$

Interpreting whether trends in HIV notifications reflect changes in incidence in the USA is complicated by the fact that rates of HIV testing outside cities with large and visible gay communities, such as San Francsico and New York, were historically relatively low, resulting in a high proportion of HIV infected men being undiagnosed. In a survey of 15- to 29-year-old homosexual men in six American cities in 1994-2000, $77 \%$ of all men diagnosed with HIV were previously unaware of their infection. ${ }^{38}$ However, rates of HIV testing have increased substantially among homosexual men in the USA in recent years. In the late $1990 \mathrm{~s}, 54 \%$ of MSM interviewed at community-based venues had been tested for HIV in the last year. ${ }^{39}$ By 2004, a study of similar methodology reported that this had increased to $64 \%$, and $92 \%$ had been previously tested at least once. ${ }^{35}$

\section{New Zealand}

\section{Surveillance data}

The number of diagnoses of HIV in homosexual men in New Zealand more than doubled between 2000 (30 cases) and 2005 ( 88 cases). ${ }^{40,41}$

\section{Data from epidemiological studies}

There have been no studies which have provided a direct measure of HIV incidence in homosexual men in New Zealand. In 2006, self-reported HIV prevalence in Auckland was 5\% among those who had been HIV tested, but a high proportion, more than $30 \%$, had never been tested. ${ }^{40}$ Only $39 \%$ had received HIV testing in the past 12 months. Rates of HIV testing increased only minimally since $2002 .^{40}$

\section{Australia}

\section{Surveillance data}

HIV notifications in Australia declined consistently between the mid 1980s and the late 1990s, but have increased $31 \%$ from 2000 to 2006 . $^{2}$ Until the late 1990 s, trends were similar across major Australian jurisdictions, but since 1998 there has been a marked divergence with close to a $100 \%$ increase in HIV diagnoses among homosexual men in Victoria, a less marked increase in Queensland, and a stabilisation in the number of diagnoses in the largest jurisdiction, New South Wales. ${ }^{2}$

\section{Data from epidemiological studies}

Data from a community-based cohort in Sydney suggest that the HIV incidence in gay-community attached men was slightly under $1 \%$ per year in the period $2001-2006 .{ }^{42}$ Much higher incidence was described in community and clinic-based cohort studies in the 1980s and early 1990s, ${ }^{43,44}$ and this is consistent with back-projection estimates that HIV incidence peaked in Australia in the mid 1980s and then rapidly declined. ${ }^{45}$ No estimates of HIV incidence based on the STARHS algorithm have been published from Australia.

Self-reported HIV prevalence in community-based samples of gay men is slightly higher in Sydney than elsewhere, but is now less than $10 \%$ in all major cities. There is evidence that HIV prevalence is declining in younger gay men in Sydney. ${ }^{46} \mathrm{HIV}$ testing rates have been historically very high in Australia. Over the past decade, approximately $90 \%$ of gay men recruited in community-based surveys have consistently reported a history of HIV testing, with $60 \%$ or more reporting HIV testing in the past year. ${ }^{47}$ In the past 5 years, there has been a further slight increase in testing rates. ${ }^{48}$

\section{Discussion}

Where long-standing HIV surveillance data exist, notifications of HIV diagnoses are increasing in homosexual men in almost all developed countries. Whether or not this reflects a similarly universal increase in HIV incidence is less certain. In some locations, for example the USA, Canada and the UK, rates of HIV testing have increased markedly in homosexual men, and this trend may at least partly explain the increases in diagnoses. Nevertheless, direct measures of HIV incidence based on repeat testers in clinic- and community-based cohorts do suggest that increases in HIV incidence are occurring in homosexual men in North America and Europe. Although not the focus of this article, there is also surveillance evidence of increasing HIV diagnoses in homosexual men in Asian countries, including both developed regions such as $\mathrm{Japan}^{49}$ and Hong Kong ${ }^{50}$ and developing countries such as Thailand. ${ }^{51}$

One approach to assess whether the increases in HIV notification reflect increases in HIV incidence is to triangulate these data with data on related infections and on HIV-related risk behaviours in homosexual men. With regard to behaviour, available data paint a clear picture of increasing HIV risk. HIV-related risk behaviour has been reported to be 
increasing since the mid 1990s in almost all those jurisdictions which collect such data. ${ }^{52}$ In addition, rates of sexually transmissible infections (STI) other than HIV are also on the increase in the great majority of these locations, including increasing rates of gonorrhoea, chlamydia and infectious syphilis. $^{53}$

Australia is fortunate to have data on newly diagnosed HIV since the late 1980s, data on newly acquired HIV since $1991,{ }^{54,55}$ and annually collected self-report data on sexual risk behaviour, HIV testing behaviour, and HIV prevalence in homosexual men since the mid 1990s. ${ }^{56}$ Australia's national pattern of increasing notifications of newly diagnosed $\mathrm{HIV}^{2}$ is clearly consistent with international trends. Cohort-based estimates of HIV incidence in Australia, currently just under $1 \%,{ }^{42}$ appear lower than USA estimates, and are also lower than in the largest European community-based cohort. ${ }^{11}$ The HIV prevalence in homosexual men in large Australian cities is now less than $10 \%$ in all cities, ${ }^{46}$ and this is substantially lower than in the USA $(18-40 \%),{ }^{35}$ and somewhat lower than recent European estimates (mostly 10-15\%). ${ }^{16}$ Australian rates of HIV testing have been consistently high, ${ }^{48}$ and have not shown the dramatic increases since the late 1990s seen in some North American and European locations. The pattern in New South Wales, with a constant rate of HIV notification, ${ }^{2}$ a constant rate of HIV infection in a community-based cohort, ${ }^{42}$ declining HIV prevalence in the young, ${ }^{46}$ and declining HIV risk behaviour, ${ }^{57}$ appears to be unique.

This review of time trends in HIV in homosexual men in developed countries has some limitations. In terms of surveillance, long-term population-based data are not available for many jurisdictions within the areas covered. Internationally, there has been a movement towards increasing the coverage of HIV surveillance, as it is increasingly appreciated that AIDS surveillance provides a substantially incomplete picture of the extent of the HIV epidemic, and cannot inform discussions of the success or failure of current HIV prevention interventions. In terms of direct measures of HIV incidence, there were few cohort studies conducted this century which allowed an assessment of trends in HIV incidence. It is possible that the publication of HIV incidence data from STI clinics may be subject to publication bias, with a tendency for authors to submit manuscripts, and journals to accept them, if they report an increase in incidence rather than a constant incidence. The STARHS approach overestimates HIV incidence when, on average, the blood samples have been collected soon after a HIV risk event rather than midway through the window period. ${ }^{58}$ This is very likely to be the case for most estimates based on samples collected at STI clinics, where people present soon after a risk episode because of an acute STI or because of worry related to a HIV risk episode. Interpreting time trends in STARHS estimates of HIV incidence is likely to be even more problematic at a time of increasing frequency of HIV testing in many settings.

In conclusion, there is a near-universal increase in notification of HIV diagnoses in homosexual men in the developed world. Based on incomplete data, it appears likely that a true increase in HIV incidence underlies these increases in HIV diagnoses in most locations. Determining the degree and extent of the increases in incidence in homosexual men is an issue of crucial importance in developing appropriate public health responses in the evolving HIV epidemic. Increased attention to the surveillance of HIV incidence is required, including regular collection of data on rates of HIV testing, more universal collection of data on new HIV diagnoses, the investigation of the use of biological assays for HIV incidence, and specific epidemiological studies to examine HIV incidence in populations of homosexual men.

\section{Conflict of interest}

Professor Grulich is Chair of the NSW Health Department HIV Health Promotion Committee.

\section{Acknowledgements}

The National Centre in HIV Epidemiology and Clinical Research (NCHECR) is funded by the Australian Government Department of Health and Ageing, and is affiliated with the Faculty of Medicine, University of New South Wales.

\section{References}

1 National Centre in HIV Epidemiology and Clinical Research. HIV/AIDS, viral hepatitis, and sexually transmissible infections in Australia Annual Surveillance Report 2006. Available online at: http://www.nchecr.unsw.edu.au/NCHECRweb.nsf/resources/ SurvReports_4/\$file/06_ansurvrp_rev.pdf [verified 29 February 2008].

2 Guy RJ, McDonald AM, Bartlett MJ, Murray JC, Giele CM, Davey TM, et al. HIV diagnoses in Australia: diverging epidemics within a low-prevalence country. Med J Aust 2007; 187: 1-4.

3 Janssen RS, Satten GA, Stramer SL, Rawal BD, O'Brien TR, Weiblen BJ, et al. New testing strategy to detect early HIV-1 infection for use in incidence estimates and for clinical and prevention purposes. JAMA 1998; 280: 42-8. doi: 10.1001/ jama.280.1.42

4 EuroHIV. HIV/AIDS surveillance in Europe. End-year report 2005. Saint-Maurice: Institut de veille sanitarie; 2006.

5 Hamers FF, Downs AM. The changing face of the HIV epidemic in Western Europe: what are the implications for public health policies? Lancet 2004; 364: 83-94. doi: 10.1016/S0140-6736(04)16594-X

6 Hamers FF, Infuso A, Alix J, Downs AM. Current situation and regional perspective on HIV/AIDS surveillance in Europe. $J$ Acquir Immune Defic Syndr 2003; 32: S39-48.

7 del Romero J, Castilla J, Garcia S, Clavo P, Ballesteros J, Rodriguez C. Time trend in incidence of HIV seroconversion among homosexual men repeatedly tested in Madrid, 1988-2000. AIDS 2001; 15: 1319-21. doi: 10.1097/00002030200107060-00019

8 Barrasa A, Castilla J, del Romero J, Pueyo I, de Armas C, Varela JA, et al. Sentinel surveillance of HIV infection in HIV test clinics, Spain 1992-2002. Euro Surveill 2004; 9: 27-9.

9 Giuliani M, Di Carlo A, Palamara G, Dorrucci M, Latini A, Prignano $\mathrm{G}$, et al. Increased HIV incidence among men who have sex with men in Rome. AIDS 2005; 19: 1429-31. doi: 10.1097/ 01.aids.0000180808.27298.af

10 Hurtado I, Alastrue I, Ferreros I, del Amo J, Santos C, Tasa T, et al. Trends in HIV testing, serial HIV prevalence and HIV incidence among people attending a Center for AIDS Prevention from 1988 to 2003. Sex Transm Infect 2007; 83: 23-8. doi: 10.1136/ sti.2005.019299 
11 Dukers NH, Fennema HS, van der Snoek EM, Krol A, Geskus RB, Pospiech M, et al. HIV incidence and HIV testing behavior in men who have sex with men: using three incidence sources, The Netherlands, 1984-2005. AIDS 2007; 21: 491-9. doi: 10.1097/ QAD.0b013e328011dade

12 Dukers NH, Spaargaren J, Geskus RB, Beijnen J, Coutinho RA, Fennema HS. HIV incidence on the increase among homosexual men attending an Amsterdam sexually transmitted disease clinic: using a novel approach for detecting recent infections. AIDS 2002; 16: F19-24. doi: 10.1097/00002030200207050-00001

13 Murphy G, Charlett A, Brown AE, Gill ON, Parry JV. Is HIV incidence increasing in homo/bisexual men attending GUM clinics in England, Wales and Northern Ireland? Commun Dis Public Health 2004; 7: 11-4.

14 Murphy G, Charlett A, Jordan LF, Osner N, Gill ON, Parry JV. HIV incidence appears constant in men who have sex with men despite widespread use of effective antiretroviral therapy. AIDS 2004; 18: 265-72. doi: 10.1097/00002030-200401230-00016

15 Dougan S, Elford J, Chadborn TR, Brown AE, Roy K, Murphy G, et al. Does the recent increase in HIV diagnoses among men who have sex with men in the UK reflect a rise in HIV incidence or increased uptake of HIV testing? Sex Transm Infect 2007; 83: 120-5. doi: $10.1136 /$ sti.2006.021428

16 EuroHIV. HIV/AIDS surveillance in Europe. Mid year report 2005 (Report No. 72). Saint-Maurice: Institut de veille sanitaire; 2006.

17 Marcus U, Voss L, Kollan C, Hamouda O. HIV incidence increasing in MSM in Germany: factors influencing infection dynamics. Euro Surveill 2006; 11: 157-60.

18 Stolte IG, de Wit JB, Kolader ME, Fennema HS, Coutinho RA, Dukers NH. Low HIV-testing rates among younger high-risk homosexual men in Amsterdam. Sex Transm Infect 2007; 83: 387-91. doi: 10.1136/sti.2005.019133

19 Canadian Sexually Transmitted Infections Surveillance Report. Can Commun Dis Rep 2007; 33: 1-69.

20 Haag D, Kim P, Spencer D, Williams C, Wong E, Knowles L, Rekart ML. HIV/AIDS Update, year end 2004. Vancouver: British Columbia Centre for Disease Control, STD/AIDS control; 2006.

21 Remis RS, Swantee C, Schiedel L, Merid MF, Liu J. Report on HIV/AIDS in Ontario 2004. Toronto: Ontario HIV Epidemiologic Monitoring Unit, Department of Public Health Sciences, University of Toronto; 2006.

22 Remis RS, Alary M, Otis J, Masse B, Demers E, Vincelette J, et al. No increase in HIV incidence observed in a cohort of men who have sex with other men in Montreal. AIDS 2002; 16: 1183-5. doi: 10.1097/ 00002030-200205240-00014

23 Hogg RS, Weber AE, Chan K, Martindale S, Cook D, Miller ML, et al. Increasing incidence of HIV infections among young gay and bisexual men in Vancouver. AIDS 2001; 15: 1321-2. doi: 10.1097/ 00002030-200107060-00020

24 Calzavara L, Burchell AN, Major C, Remis RS, Corey P, Myers T, et al. Increases in HIV incidence among men who have sex with men undergoing repeat diagnostic HIV testing in Ontario, Canada. AIDS 2002; 16: 1655-61. doi: 10.1097/00002030200208160-00011

25 Public Health Agency of Canada. HIV infections among MSM in Canada. In: HIV/AIDS Epi Udpates, August 2006. Ottawa: Surveillance and Risk Assessment Division, Centre for Infectious Disease Prevention and Control, Public Health Agency of Canada; 2006. pp. 63-73.

26 Myers T, Allman D, Calzavara L, Maxwell J, Remis R, Swantee C, et al. Ontario men's survey final report. Toronto: University of Toronto, HIV Social, Behavioural and Epidemiological Studies Unit; 2004.
27 Hall HI, Song R, McKenna MT. Increases in HIV diagnoses-29 States, 1999-2002. Morb Mortal Wkly Rep 2003; 52: 1145-8.

28 Centers for Disease Control and Prevention HIV/AIDS Surveillance Report 2005. Vol 17. Atlanta: US Department of Health and Human Services, Centers for Disease Control and Prevention; 2006.

29 Espinoza L, Hall H, Campsmith ML, Lee LM. Trends in HIV/AIDS Diagnoses-33 States, 2001-2004. Morb Mortal Wkly Rep 2005; 54 : 1149-53.

30 Glynn MK, Lee LM, McKenna MT. The status of national HIV case surveillance, United States 2006. Public Health Rep 2007; 122: 63-71.

31 Vu MQ, Steketee RW, Valleroy L, Weinstock H, Karon J, Janssen R. HIV incidence in the United States, 1978-1999. J Acquir Immune Defic Syndr 2002; 31: 188-201.

32 Koblin B, Chesney M, Coates T. Effects of a behavioural intervention to reduce acquisition of HIV infection among men who have sex with men: the EXPLORE randomised controlled study. Lancet 2004; 364 : 41-50. doi: 10.1016/S0140-6736(04)16588-4

33 Truong HM, Kellogg T, Klausner JD, Katz MH, Dilley J, Knapper K, et al. Increases in sexually transmitted infections and sexual risk behaviour without a concurrent increase in HIV incidence among men who have sex with men in San Francisco: a suggestion of HIV serosorting? Sex Transm Infect 2006; 82: 461-6. doi: 10.1136/ sti.2006.019950

34 Valleroy LA, MacKellar DA, Karon JM, Rosen DH, McFarland W, Shehan DA, et al. HIV prevalence and associated risks in young men who have sex with men. Young Men's Survey Study Group. JAMA 2000; 284: 198-204. doi: 10.1001/jama.284.2.198

35 Sifakis F, Flynn CP, Metsch L, LaLota M, Murrill C, Koblin BA, et al. HIV prevalence, unrecognized infection, and HIV testing among men who have sex with men-five U.S. cities, June 2004-April 2005. Morb Mort Wkly Rep 2005; 54: 597-601.

36 Osmond DH, Pollack LM, Paul JP, Catania JA. Changes in prevalence of HIV infection and sexual risk behavior in men who have sex with men in San Francisco: 1997-2002. Am J Public Health 2007; 97 : 1677-83. doi: 10.2105/AJPH.2005.062851

37 Xia Q, Osmond DH, Tholandi M, Pollack LM, Zhou W, Ruiz JD, et al. HIV prevalence and sexual risk behaviors among men who have sex with men: results from a statewide population-based survey in California. J Acquir Immune Defic Syndr 2006; 41: 238-45. doi: 10.1097/01.qai.0000185574.98472.36

38 MacKellar DA, Valleroy LA, Secura GM, Behel S, Bingham T, Celentano DD, et al. Unrecognized HIV infection, risk behaviors, and perceptions of risk among young men who have sex with men: opportunities for advancing HIV prevention in the third decade of HIV/AIDS. J Acquir Immune Defic Syndr 2005; 38: 603-14. doi: 10.1097/01.qai.0000141481.48348.7e

39 MacKellar DA, Valleroy LA, Anderson JE, Behel S, Secura GM, Bingham $\mathrm{T}$, et al. Recent HIV testing among young men who have sex with men: correlates, contexts, and HIV seroconversion. Sex Transm Dis 2006; 33: 183-92. doi: 10.1097/01.olq.0000204507. 21902.b3

40 Saxton P, Dickson N, Hughes A. GAPSS 2006: Findings from the Gay Auckland Periodic Sex Survey. Auckland: New Zealand AIDS Foundation; 2006.

41 Dickson N, Davidson OJ. HIV prevention in New Zealand-still room for improvement. $N Z$ Med $J$ 2006; 119: U2250.

42 Jin F, Prestage G, McDonald A, Ramacciotti T, Imrie JC, Kippax SC, et al. Trends in HIV incidence in a cohort of homosexual men in Sydney: data from the HIM Study. Sex Health 2008; 5: 109-12. doi: $10.1071 / \mathrm{SH} 07073$

43 Kaldor J, Williamson P, Guinan JJ, Imrie A, Gold J. Falling incidence of HIV infection in a cohort of clinic attenders. Aust J Public Health 1993; 17: 334-8. 
44 Burcham JL, Tindall B, Marmor M, Cooper DA, Berry G, Penny R. Incidence and risk factors for human immunodeficiency virus seroconversion in a cohort of Sydney homosexual men. Med $J$ Aust 1989; 150: 634-9.

45 Becker NG, Watson LF, Marschner IC, Motika M, Newstead SV, Carlin JB. Assessing the extent of the Australian HIV epidemic from AIDS surveillance data. Aust J Public Health 1993; 17: 226-31.

46 Prestage G, Jin F, Zablotska I, Imrie J, Kaldor JM, Grulich AE. Trends in HIV prevalence among homosexual and bisexual men in eastern Australian states. Sex Health 2008; 5: 103-7. doi: 10.1071/SH07074

47 Jin FY, Prestage G, Law MG, Kippax S, Van de Ven P, Rawsthorne P, et al. Predictors of recent HIV testing in homosexual men in Australia. HIV Med 2002; 3: 271-6. doi: 10.1046/j.1468-1293.2002.00121.x

48 Prestage G, Zablotska I, Imrie J, Grulich AE, Pitts M. Trends in HIV testing among homosexual and bisexual men in eastern Australian states. Sex Health 2008; 5: 119-23. doi: 10.1071/SH07081

49 Nemoto T. HIV/AIDS surveillance and prevention studies in Japan: summary and recommendations. AIDS Educ Prev 2004; 16: 27-42. doi: 10.1521/aeap.16.3.5.27.35529

50 Special Preventive Programme CfHP, Department of Health. FACTSHEET HIV/AIDS Situation in Hong Kong [2006]. Hong Kong: Hong Kong Department of Health; 2007.

51 van Griensven F, Thanprasertsuk S, Jommaroeng R, Mansergh G, Naorat S, Jenkins RA, et al. Evidence of a previously undocumented epidemic of HIV infection among men who have sex with men in Bangkok, Thailand. AIDS 2005; 19: 521-6. doi: 10.1097/01. aids.0000162341.50933.e8
52 Grulich A. HIV risk behaviour in gay men: on the rise? BMJ 2000; 320: 1487-8. doi: 10.1136/bmj.320.7248.1487

53 Fenton KA, Imrie J. Increasing rates of sexually transmitted diseases in homosexual men in Western Europe and the United States: why? Infect Dis Clin North Am 2005; 19: 311-31. doi: 10.1016/j. idc.2005.04.004

54 McDonald AM, Gertig DM, Crofts N, Kaldor JM. A national surveillance system for newly acquired HIV infection in Australia. National HIV Surveillance Committee. Am J Public Health 1994; 84 : 1923-8.

55 Kaldor J, McDonald A. HIV/AIDS surveillance systems in Australia. J Acquir Immune Defic Syndr 2003; 32: S18-23.

56 Van de Ven P, Prestage G, Crawford J, Grulich A, Kippax S. Sexual risk behaviour increases and is associated with HIV optimism among HIV-negative and HIV-positive gay men in Sydney over the 4 year period to February 2000. AIDS 2000; 14: 2951-3. doi: 10.1097/ 00002030-200012220-00023

57 Zablotska I, Prestage G, Grulich AE, Imrie J. Divergent trends in sexual risk behaviours in three Australian states: New South Wales, Victoria and Queensland, 1998-2006. Sex Health 2008; 5: 125-30. doi: $10.1017 / \mathrm{SH} 07076$

58 Remis RS, Palmer RW, Raboud J. Estimates of HIV incidence based on detuned assay results may be strongly biased: Evidence from a simulation study. XIV International AIDS Conference 2002 July 7-12 2002; Barcelona, Spain.

Manuscript received 27 September 2007, accepted 21 February 2008 